\title{
Source area of the 1858 earthquake swarm in the central Ryukyu Islands revealed by the observations of Father Louis Furet
}

\author{
Takuma Oda and Mamoru Nakamura* ${ }^{*}$
}

\begin{abstract}
We estimated the location and magnitude of earthquakes constituting the 1858 earthquake swarm in the central Ryukyu Islands using the felt earthquakes recorded by Father Louis Furet who lived in Naha, Okinawa Island, in the middle of the nineteenth century. First, we estimated the JMA seismic intensity of the earthquakes by interpreting the words used to describe the shaking. Next, using the seismic intensity and shaking duration of the felt earthquakes, we estimated the epicentral distance and magnitude range of three earthquakes in the swarm. The results showed that the epicentral distances of the earthquakes were $20-250 \mathrm{~km}$ and that magnitudes ranged between 4.5 and 6.5, with a strong correlation between epicentral distance and magnitude. Since the rumblings accompanying some earthquakes in the swarm were heard from a northward direction, the swarm probably occurred to the north of Naha. The most likely source area for the 1858 swarm is the central Okinawa Trough, where a similar swarm event occurred in 1980. If the 1858 swarm occurred in the central Okinawa Trough, the estimated maximum magnitude would have reached 6-7. In contrast, if the 1858 swarm occurred in the vicinity of Amami Island, which is the second most likely candidate area, it would have produced a cluster of magnitude 7-8 earthquakes.
\end{abstract}

Keywords: Seismicity, Historical earthquake, Okinawa Trough, Ryukyu Islands

\section{Introduction}

Determination of historical seismicity before the start of modern seismic observation is important for estimating the long-term probability of large earthquakes and strong ground motions (Kawasumi 1951; Kanai and Suzuki 1968; Frankel et al. 1996; Headquarters for Earthquake Research Promotion 2005; Miyazawa and Mori 2009). Analysis of old literature provides information on historical seismicity. The distribution of damaged houses, degree of shaking, and various phenomena caused by earthquakes indicate the epicenter and fault locations and earthquake magnitude. For example, magnitude and hypocenters of the 1811-1812 New Madrid earthquakes and the 1855 Ansei Edo earthquake were estimated using an intensity distribution approximated from shaking and damage reports (Bakun and Hopper 2004; Bakun 2005;

\footnotetext{
*Correspondence: mnaka@sci.u-ryukyu.ac.jp

Faculty of Science, University of the Ryukyus, 1 Senbaru, Nishihara-cho, Okinawa 903-0213, Japan
}

Nakamura and Matsuura 2011). Moreover, these records sometimes provide insights into people's behavior during and after an earthquake.

The "Kyuyo," which was the official document of the Ryukyu Kingdom, has been used to analyze historical earthquakes and tsunamis in the Ryukyu Islands region (Kyuyo-Kenkyu-kai 1974). Earthquakes that occurred in the Ryukyu Kingdom from 1664 to 1858 were recorded in the "Kyuyo." The latest documented earthquakes constitute the 1858 earthquake swarm, which we analyze in this paper using the reports of Father Louis Furet. The 1858 earthquake swarm was recorded in the "Kyuyo" as follows: "The earthquake shakings were felt frequently from August to December of 1858 in the lunar calendar. In that time, the shaking was felt seven or eight times or five or six times during the whole day and night. Something akin to sound accompanying the shaking was observed." However, since the seismic intensity and the duration of shaking were not recorded, we could not estimate the details of these events. 
In the middle of the nineteenth century, people from the USA, France, and the Netherlands stayed in Naha, Okinawa Island, to conclude a treaty of commerce with the Ryukyuan people, or for Christian missionary work (Fig. 1). Several of these inhabitants left records of the earthquakes in Naha. Furet, whose reports we analyze in this study, was one of them (Beillevaire 1999, 2013; Demarée et al. 2016). Furet arrived in Okinawa from Hong Kong in February 1855. Furet observed weather from April 1855. He lived in the Seigenji Temple, located in the north of Naha (Demarée et al. 2016) (Fig. 1). He returned to Hong Kong in May 1855, and subsequently returned to Naha again in 1856. After the Treaty of Amity between the Ryukyu Kingdom and France was signed in November 1855, French inhabitants moved their residence to Matsuyama, Naha, in February 1856 (Historiographical Institute, Okinawa Prefectural Library 1984) (Fig. 1). Furet started weather observations there and recorded the felt earthquakes from 1857 until Furet left Naha in October 1862 (Beillevaire 1999, 2013). The records were written in French, and they have now been found and published by Demarée et al. (2016). The period of observation approximately corresponds to the period of the 1858 swarm, which was also recorded in the "Kyuyo." Using these records, we analyzed the seismicity in Naha from 1857 to 1860 , and investigated the 1858 earthquake swarm.

\section{Data and method}

The recorded felt events were duplicated in three types of document. These are: (1) the abstracts, "les feuilles de synthese"; (2) the monthly reports, "les résumés du mois"; and (3) the list published by Sainte-Claire Deville in the accounts of the Academy of Sciences in 1859, "la liste publiée par Sainte-Claire Deville dans les comptes rendus de l'Académie des sciences en 1859." Demarée et al. (2016) compiled these three catalogues into a single list. There was little difference in the description of the events between the three catalogues. The event information, comprising occurrence date and time and degree of seismic shaking, was recorded in the report. The occurrence time of the felt events was generally recorded in units of $15 \mathrm{~min}$, although that of some events was recorded in 1-min units. For some events, the duration of the shaking and rumbling, and the direction of the rumbling sound, was also recorded. The event report started from March 1857 and ended in August 1860.

First, we picked words relating to ground shaking from the reported observations (Additional file 1: Table S1).

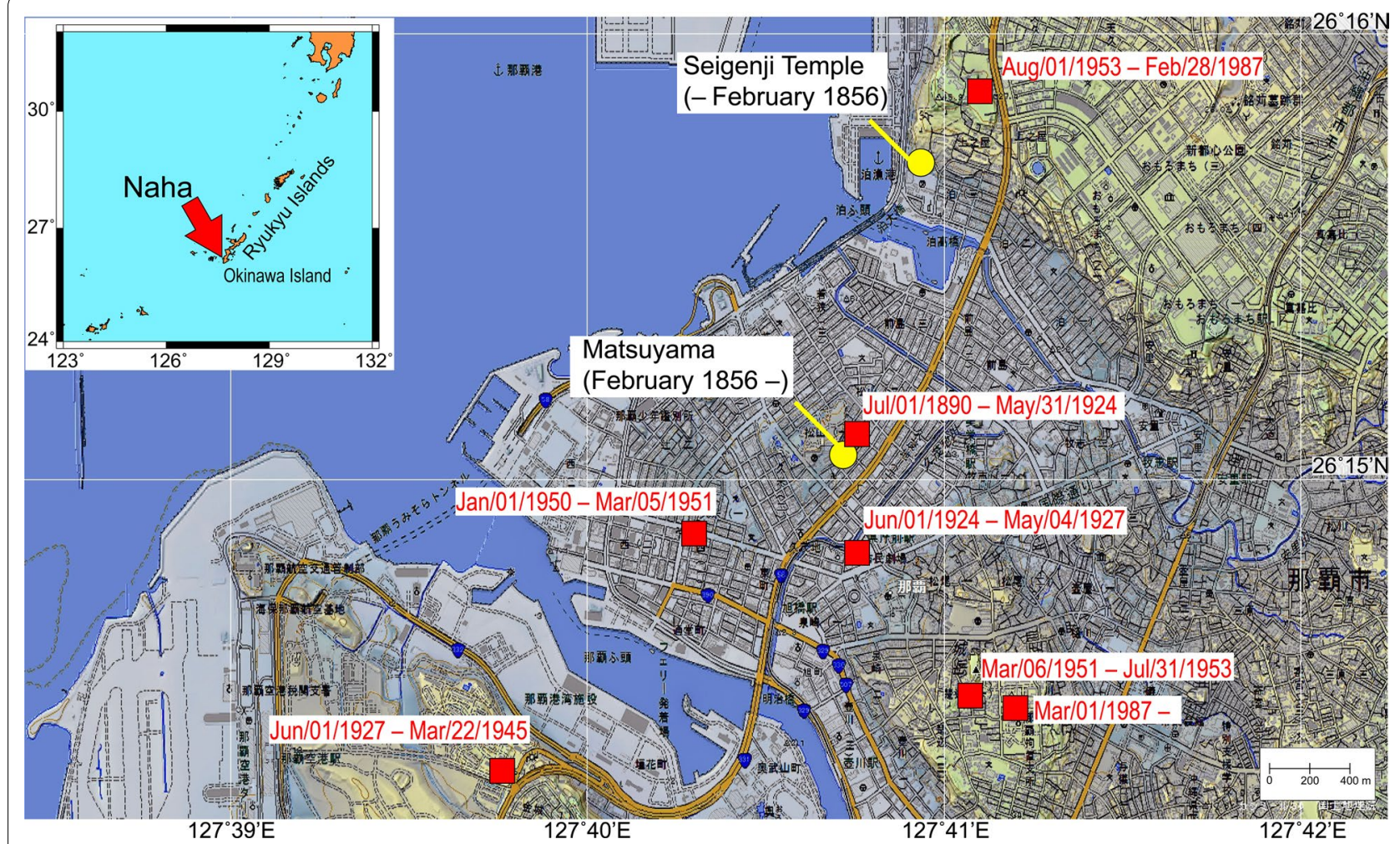

Fig. 1 Map of French residences and JMA intensity observation points in Naha, Okinawa Island. Yellow circles show the French residences. Red rectangles show the JMA intensity observation points. Red annotations denote the observation periods for the JMA points. National Land Numerical Information data provided by the Geospatial Information Authority of Japan 
The degrees of seismic intensity were categorized from strongest to weakest using five phrases as follows: "violente secousse," "forte secousse," "secousse assez forte," "légère secousse," and "la secousse." However, the damage to houses caused by the shaking was not reliably documented in the report. For example, for the event at 10:27 on January 6,1858 , Furet described that "the whole wooden house cracked and the swings were felt enough so that we could feel them on their seats." Based on this description, we estimated a seismic intensity for this event of 2 on the JMA seismic intensity scale. The JMA seismic intensity scales of 2,3 , and 4 correspond to peak ground accelerations of 3.3-11, 11-41, and 41-147 cm/ $\mathrm{s}^{2}$, respectively (Fujimoto and Midorikawa 2005). In contrast, for the event of November 14, 1858, the shaking was described as "violente secousse." This was the strongest shaking recorded; however, no house damage was documented. Therefore, we interpreted the phrase "violente secousse" as corresponding to seismic intensity 4 on the JMA scale.

Next, we assigned the other phrases to categories 1-3 on the JMA seismic intensity scale. The phrases "forte secousse" and "fort tremblement" were designated as intensity 3; "secousse assez forte" was designated as intensity 2; and "légère secousse" and "secousse" were designated as intensity 1 . The events without descriptions were also designated as intensity 1 . Then, we converted all the event descriptions to the JMA seismic intensity scale using the above conversion.

\section{Estimation of epicenter location and magnitude}

During the observation period, both the intensity and the duration of shaking were recorded for 11 events. Of these, three events occurred during the swarm period: (1) For the event at 2:30 on September 22, 1858, the seismic intensity and the duration were 3 and at least $60 \mathrm{~s}$, respectively; (2) for the event at 20:00 on October 29, 1858 , the seismic intensity and the duration were 3 and $60 \mathrm{~s}$, respectively; (3) for the event at 15:36 on November 7,1858 , the seismic intensity and the duration were 3 and $60-120 \mathrm{~s}$, respectively. Since the durations of some felt events were recorded in 1-min units, it seems that the intuitive time measurement of $1 \mathrm{~min}$ by bodily sense was similar to that of the present day. Therefore, the time duration measurements can be used as rough estimations of the shaking duration with a measurement error in the order of 10-20 s.

We then estimated the epicentral distance and magnitude of these three events using the seismic intensity and the duration of shaking. We computed the theoretical seismic intensity and duration of shaking using empirical formulas by changing the magnitude and distance. Using the results, we searched the ranges of magnitude and epicentral distance of the events for which both the intensity and the duration are consistent with the observed ones.

\section{Calculation of duration of ground motion}

To calculate the duration of ground motion, we utilized the empirical equation of Nojima (2014), which predicts the duration of a specific JMA seismic intensity under given values of predicted or observed JMA seismic intensity. We employed their Model B (Eq. 3; Nojima 2014) because this model performs best at low minimum intensity thresholds, as follows:

$$
\begin{aligned}
\log _{10} D_{\mathrm{UAI}}= & i_{1} \cdot \log _{10} \Delta I+i_{2} \cdot\left(\log _{10} \Delta I\right)^{2}+m \cdot M w+r \cdot \log _{10} R \\
& +v \cdot \log _{10} \mathrm{AVS}_{30}+z \cdot \log _{10} Z_{1.4}+\sum_{k} F_{k} \cdot f_{k} \pm \sigma
\end{aligned}
$$

where $D_{\mathrm{UAI}}$ is the duration, $\Delta I$ is the intensity difference, $M w$ is the moment magnitude, $R$ is the distance, $\mathrm{AVS}_{30}$ is the average $\mathrm{S}$-wave velocity up to $30 \mathrm{~m}$ depth, and $Z_{1.4}$ is the top depth of the layer with $V s=1400 \mathrm{~m} / \mathrm{s}$. The parameters $i_{1}, i_{2}, m, r, n, z, F_{k}, f_{k}$, and $\sigma$ define Model B of Nojima (2014). We used these parameters when the threshold minimum intensity was 0.5 . Here, $\Delta I$ was set to $2.5 ; A \mathrm{VS}_{30}$ and $Z_{1.4}$ were set to $187 \mathrm{~m} / \mathrm{s}$ and $300 \mathrm{~m}$, respectively, which were chosen based on the Japan Seismic Hazard Information Station (J-SHIS) (Headquarters for Earthquake Research Promotion 2005; Wakamatsu and Matsuoka 2013) in the area where Furet made his observations (Fig. 1), and we computed the duration for a magnitude range of 4.0-8.5 and a distance range of $0-600 \mathrm{~km}$.

\section{Calculation of seismic intensity}

To calculate the seismic intensity, we first computed the peak ground velocity for the depth at which the shear wave velocity is $600 \mathrm{~m} / \mathrm{s}\left(\mathrm{PGV}_{600}\right)$ using the equation of Si and Midorikawa (1999):

$$
\begin{aligned}
\log \mathrm{PGV}_{600}= & 0.58 \mathrm{Mw}+0.0038 \mathrm{D}-1.29 \\
& -\log \left(X+0.0028 \times 10^{0.50 M w}\right)-0.002 X
\end{aligned}
$$

where $D$ is the depth, and $X$ is the epicentral distance of the earthquake. We assumed a crustal earthquake, and set the depth to $30 \mathrm{~km}$ accordingly. In the case of slab earthquakes and interplate earthquakes, the seismic intensity increases by 0.2 and -0.04 , respectively.

Then we computed the site amplification factor (ARV) using the following equation (Fujimoto and Midorikawa 2005):

$$
\log \mathrm{ARV}=2.367-0.852 \log \mathrm{AVS}_{30} \pm 0.166
$$


As above, $\mathrm{AVS}_{30}$ was set to $187 \mathrm{~m} / \mathrm{s}$ (J-SHIS).

Then, we computed the surface shear wave velocity (PGV) using the equation:

$$
\mathrm{PGV}=\mathrm{PGV}_{600} \times \mathrm{ARV}
$$

Finally, we computed the JMA seismic intensity $(I)$ using the equation (Fujimoto and Midorikawa 2005): the rumbling or sound was observed during the swarm period was $35 \%$. This is higher than the proportion of those for the total observation period (20\%). For the events of November 14 and December 12, 1858, the rumbling could be heard from a northward direction (Additional file 1: Table S1).

$$
\begin{cases}I=2.165+2.262 \log _{10}(\mathrm{PGV}) \pm 0.431 & (I<4) \\ I=2.002+2.603 \log _{10}(\mathrm{PGV})-0.213 \log _{10}(\mathrm{PGV})^{2} \pm 0.344 & (I>4)\end{cases}
$$

As above, we computed the intensity for a magnitude range of 4.0-8.5 and a distance range of $0-600 \mathrm{~km}$.

\section{Results}

\section{Temporal variation of felt events}

The number of events in each seismic intensity category $(1,2,3$, and 4$)$ was $26,4,8$, and 7 , respectively. The events were concentrated in the time period from October 1858 to January 1859 (Fig. 2). This suggests that these events constitute the earthquake swarm. The time series of the earthquake swarm based on the seismic intensity is as follows: First, two events with a seismic intensity of 3 were observed on October 29, 1858. Following this, events with a seismic intensity of 4 were observed on November 14 and 16,1858 . The monthly number of felt events peaked ( 7 events/month) in December 1858. Finally, two felt events with an intensity of 3 were observed on January 19 and 25, 1859 .

Accompanying these swarm events, underground rumbling or sound preceding the ground shaking was frequently observed. The proportion of events for which

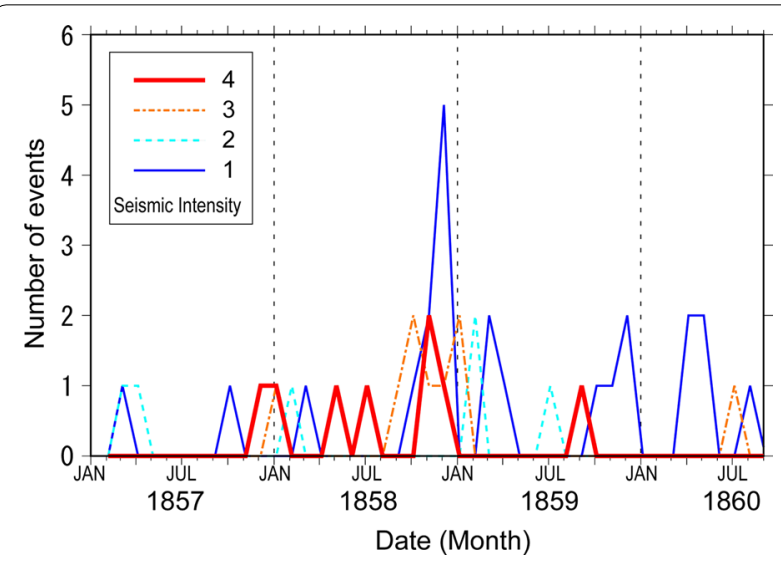

Fig. 2 Monthly number of events in each seismic intensity class. Blue, cyan dotted, orange dot dashed, and red bold lines show the monthly number of events corresponding to JMA seismic intensities of 1, 2, 3, and 4 , respectively

\section{Estimation of epicentral distance and magnitude of the swarm events}

Among all the events, the estimated range of epicentral distance and magnitude for the event of October 29, 1858, was the narrowest (Fig. 3b). The calculated area for a seismic intensity range of $3(2.5-3.5)$ is shown by red solid lines and red filled area in Fig. 3b. The $1-\sigma$ error ranges are shown by red dotted lines. In addition, Fig. $3 \mathrm{~b}$ shows the calculated area for a duration of $60 \mathrm{~s} \pm 1 \sigma$ by blue solid and dotted lines. The area for the seismic intensity ranging from $2.5-1 \sigma$ to $3.5+1 \sigma$ and the duration of $60 \mathrm{~s} \pm 1 \sigma$ ranges between M 4.3-6.5 and a distance of 20-240 km (Fig. 3b), which shows a strong correlation between epicentral distance and magnitude. In the case of the event of November 7, 1858 (Fig. 3c), the area for the seismic intensity ranging from $2.5-1 \sigma$ to $3.5+1 \sigma$ and the duration of $60-120 \mathrm{~s} \pm 1 \sigma$ ranges between $M$ $4.3-8.0$ and a distance of $20-550 \mathrm{~km}$ (Fig. 3c). However, in the case of the event of September 22, 1858, we could not determine the range of magnitude and epicentral distance because the upper limit of the duration is unknown (Fig. 3a). Nevertheless, for most events, the range of magnitude and epicentral distance is concentrated approximately between $4.5-6.5$ and $20-250 \mathrm{~km}$, respectively.

The rumbling before the ground shaking was heard from a northward direction (Additional file 1: Table S1). Since a previous study (Sato 1955) found that the direction of the rumbling sound approximately corresponded to the direction of the epicenter, this suggests that the epicenters were located to the north of Naha (Fig. 4a).

\section{Discussion}

Possible source area of the 1858 earthquake swarm

Using recent seismicity since 1923, we defined three possible source areas for the 1858 earthquake swarm, which are distributed to the north of Okinawa Island (Fig. 4a). These are: (1) the central Okinawa Trough (OT); (2) near Amami Island (AM); and (3) the Ryukyu Arc (RA) to the northeast of Okinawa Island.

If the 1858 swarm occurred in the OT, the azimuth of the swarm area is consistent with the observed rumbling 

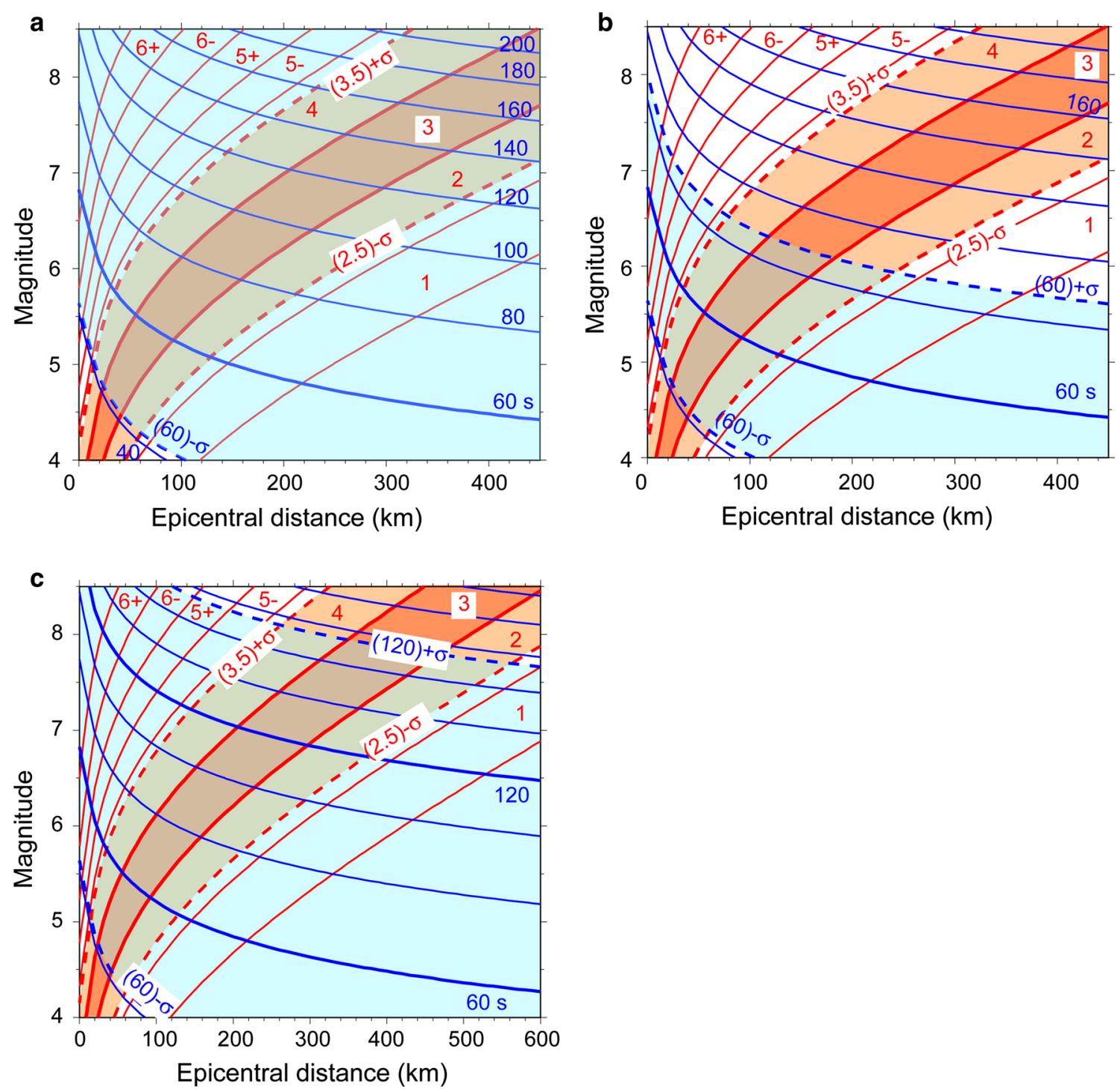

Fig. 3 Duration and seismic intensity as a function of magnitude and epicentral distance. a Earthquake at 2:30 on September 22, 1858. b Earthquake at 20:00 on October 29, 1858. c Earthquake at 15:36 on November 7, 1858. Red lines show the seismic intensity contours; thick solid and dotted red lines highlight the range of seismic intensity 3 and its error bars, respectively. Blue lines show the duration of shaking contours; blue filled area highlights the area where the shaking duration is in the range of the observed value including error bars

direction (Fig. 4a). The estimated magnitudes of events corresponding to a seismic intensity of 3 at Naha are $4.7-$ 6.7 and 6.5-8.1 for epicentral distances of $100 \mathrm{~km}$ and $300 \mathrm{~km}$, respectively (Fig. 3a-c). For a seismic intensity of 4 at Naha, the estimated magnitudes increase to 5.5-7.5 and 8 class for epicentral distances of $100 \mathrm{~km}$ and $300 \mathrm{~km}$, respectively. The magnitude range for an epicentral distance of $100 \mathrm{~km}$ is similar to the magnitude of the 1980 earthquake swarm. In the central OT, earthquakes with magnitude $>6.5$ occurred in 1931 (Mj 6.5), 1980 (Mj 6.7), and 1986 (Mj 6.5); however, there is a lack of data around the 1950s (Fig. 4b). Of these, the 1931 and 1986 events were unfelt in Naha, whereas the 1980 earthquake was felt with a seismic intensity of 2 in Naha. The 1980 swarm activity was concentrated in a 2-month period but continued for 8 months, which is similar to the case of the 1858 swarm. Thus, the possible 1858 swarm activity would have produced M 6-7 class earthquakes in the central OT.

The second possibility is that the swarm occurred near AM. The AM area is located to the northeast of Naha (Fig. 4a). This may not correspond to the observed rumbling direction; however, since the observed direction is ambiguous, this cannot rule out the 


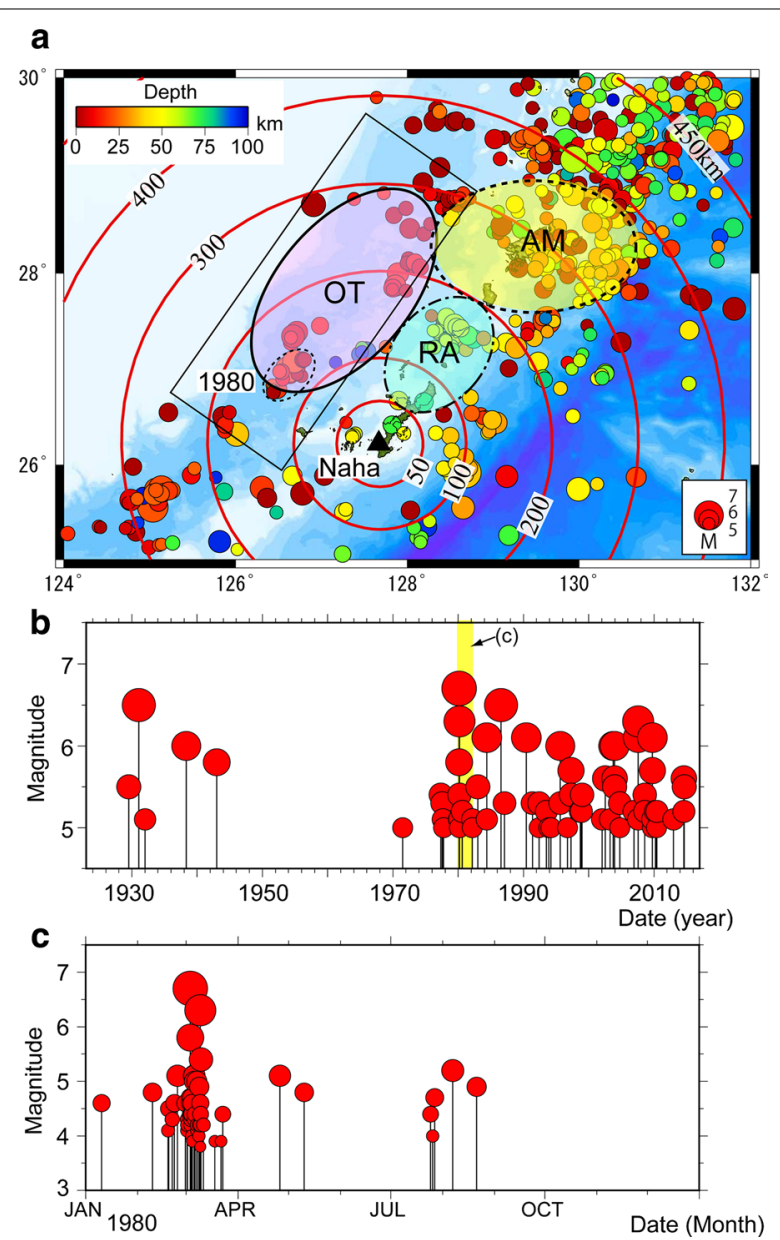

Fig. 4 Candidate source areas for the epicenters of the 1858 earthquake swarm. a Seismicity for earthquakes with magnitude $>5.0$ since 1923. Circles show the hypocenters of earthquakes shallower than $100 \mathrm{~km}$ that were catalogued by the JMA. Candidate source areas for the 1858 swarm are shown by the red solid (Okinawa Trough area: OT), yellow dotted (Amami Island area: AM), and blue dot dashed (Ryukyu Arc area: RA) ellipses. Transparent dotted ellipse denotes the epicenters of the 1980 swarm. Red-colored contours show the distance from Naha; solid black triangle shows the location of Naha. b Magnitude-time diagram for earthquakes with magnitude $>5.0$ in the central OT, denoted by the solid rectangle in (a). c Magnitudetime diagram for the 1980 swarm

possibility that the swarm occurred in the AM area. If the swarm occurred near AM, the estimated magnitudes for seismic intensities of 3 and 4 are 6.5-8.1 and 8 class, respectively, since the distance between AM and Naha is approximately $300 \mathrm{~km}$ (Fig. $3 \mathrm{a}-\mathrm{c})$. If the swarm occurred at the plate interface, the earthquake magnitudes would have been almost the same as those of a crustal earthquake. If the swarm occurred within the subducted slab, the earthquake magnitudes would have been approximately 0.2 smaller than for crustal earthquakes. Since 1900, the maximum earthquake magnitudes in the
AM area were 8, which occurred in 1911, and 7.5, which occurred in 1901. The 1911 earthquake had a seismic intensity of 5 at Naha (Imamura 1913). This magnitude is similar to the estimated earthquake magnitude for an epicentral distance of $300 \mathrm{~km}$. The 1980 swarm activity, which continued over 3 months, was not observed in this area. If the 1858 swarm occurred in the AM area, this suggests that a long-duration swarm accompanying the events with magnitude $>7.5$ occurred in this period, although long-duration activity has not been observed for the last 100 years.

If the swarm occurred in the RA, the estimated magnitudes of events with a seismic intensity of 3 are 4.0-6.0 and 5.5-7.5 for epicentral distances of $50 \mathrm{~km}$ and $200 \mathrm{~km}$, respectively. The estimated magnitudes for a seismic intensity of 4 increase to $5.0-7.0$ and 6.5-8.0 for epicentral distances of 50 and $200 \mathrm{~km}$, respectively (Fig. 3a-c). However, the recent seismic activity has been continuously low compared to other areas, and no large swarms have occurred (Fig. 4a). If the 1858 swarm occurred in the RA, this suggests that rare swarm activity occurred at that time.

Thus, the most consistent source area for the 1858 earthquake swarm is the OT. However, the possibility that the 1858 swarm occurred in the AM or RA areas cannot be excluded. Records of earthquake shaking during the 1858 swarm have not been found in AM or RA, and records of earthquake shaking before the 1901 earthquake have not been found in AM. Discovery of new records in these areas would contribute to the specification of the swarm area.

\section{Comparison with the "Kyuyo" and JMA intensity records}

The "Kyuyo" record indicates that the daily number of felt events reached 7 or 8 per day (Kyuyo-Kenkyu-kai 1974). In contrast, the records of Furet show that, although three events were recorded on December 9, 1858, there are no days when 7 or 8 felt earthquakes occurred. Instead, at 9:30 on December 9, 1858, it was stated that "the rumblings were heard many times during the day." On such a day, it is possible that all the events were recorded collectively. This suggests that the number of weak-seismic-intensity events may be undercounted for the swarm period.

Subsequently, we compared the annual number of felt events at Naha between 1857 and 1860 with that for the last 93 years recorded by the JMA. Between 1857 and 1860, the annual number of felt events was 12.9 events/year including the 1858 earthquake swarm (from October 1858 to January 1859), compared to 8.8 events/year excluding the 1858 swarm. The annual number of felt events since 1923 was $6.0 \pm 4.7$ events/ year (excluding the missing observation period from 
1945 to 1951) according to the JMA (JMA Seismic Intensity Catalogue 2017). Therefore, the annual number of felt events between 1857 and 1860 was within the variation range of that since 1923, which suggests that they were similar. However, as shown by the comparison with the "Kyuyo" record, some events may have been omitted in Furet's record when small felt events occurred continuously. This suggests that the number of small felt events may have been underestimated during the swarm. However, the degree of miscounting is likely to be low, except during the swarm period, with most of the felt events being recorded.

Differences in site amplification at the observation points would affect the value of seismic intensity and would similarly have increased or decreased the annual number of felt events. The ground amplification conditions at the observation points used by Furet and the JMA are different. From July 1, 1890, to May 4, 1927, the JMA observed the seismic intensity near the position where the Furet had made his observations (JMA 2002) (Fig. 1). The JMA observation point was moved to the western hill area from June 1927 to 1945 , and to the eastern and southern hill areas from 1950 to present; however, observations were not made between 1945 and 1949, and were made on the coastal plain area from January 1950 to March 1951 (Fig. 1). The observation points used by Furet from 1857 to 1860 and the JMA from 1890 to 1927 were located on the coastal plain, where the site amplification factor is 1.9 (J-SHIS). The seismic amplification factor in the hill area, where the JMA observed the seismic intensity since 1927, is 1.1 (J-SHIS). From Eqs. (4) and (5), this 1.7-fold increase in the seismic amplification factor generates an increase in the seismic intensity by approximately 0.4 , which increases the number of felt events. The number of observed felt events $n(I)$ for each intensity class $(I)$ at the same station is defined as follows (Nakamura 1925; Kawasumi 1952):

$$
\log n(I)=a-b I
$$

We computed the parameters $a$ and $b$ using this relation and the seismic intensity data recorded at Naha from 1923 to 2016. In the Naha area, the increase in seismic intensity of 0.4 causes a $1.65 \pm 0.11$-fold increase in the number of felt events. Therefore, the annual number of felt events between 1857 and 1860, adjusted by this site amplification effect to that at the JMA stations, is 5.3 events/year. Thus, including the difference in site amplification factor, the annual number of felt events was similar to that since 1923.

In the case of the 1980 swarm, the observed maximum seismic intensity was 2 , and intensities of 3 and 4 were not observed by the JMA at Naha, whereas, for the 1858 swarm, events with intensities of 3 and 4 were observed by Furet. As mentioned above, this difference between the 1858 and 1980 swarms may have been caused by differences in hypocenter location and the magnitude of events. Another possible cause is the difference in seismic amplification factor between the observation points of Furet and those of the JMA. Since the difference in ground amplification factor causes a 0.4-fold increase in seismic intensity, this effect may also explain the lower maximum intensity of the 1980 swarm compared to that of the 1858 swarm.

\section{Conclusions}

From analysis of the felt events recorded by Furet, we obtained the sequence of earthquake swarm activity in the central Ryukyu Islands from 1857 to 1860 . Moreover, using the calculated seismic intensity and duration of shaking, we estimated the magnitude and epicentral distance of earthquakes that constituted the swarm. The results showed that the swarm probably occurred to the north of Naha; the most likely candidate area is the OT, and the second most likely areas are near AM and the RA.

Thus, the scientific records of foreigners who stayed in Naha at that time contributed to clarifying the earthquake activity in nineteenth-century Okinawa, where the number of literatures documenting the felt earthquakes is small. Using only the "Kyuyo" record, we could not estimate the hypocenter locations and their magnitudes. However, information on the degree of shaking, duration of shaking, and rumbling direction, which were recorded by Furet, revealed the swarm area and the maximum magnitude. New data, in addition to Furet's report, may yet be provided by the observations of other foreign residents in Naha in the middle of the nineteenth century. Finding such documents and analyzing historical earthquakes would contribute to understanding the unsolved long-term seismicity in the Ryukyu area.

\section{Additional file}

Additional file 1: Table S1. List of the felt events that were recorded at Naha by Furet from 1857 to 1860 and compiled by Demarée et al. (2016), and the estimated JMA seismic intensities.

\section{Abbreviations \\ AM: Amami Island area; JMA: Japan Meteorological Agency; OT: Okinawa Trough area; RA: Ryukyu Arc area.}

\section{Authors' contributions}

TO undertook the analysis and interpretation, and prepared the draft in Japanese. MN carried out additional analyses, prepared the English manuscript, and constructed the figures included in this work. Both authors read and approved the final manuscript. 


\section{Acknowledgements}

We thank two anonymous reviewers whose comments helped to improve and refine the manuscript significantly. We used the freeware program "Kashmir 3D" (Sugimoto 2000), and National Land Numerical Information data provided by the Geospatial Information Authority of Japan, to produce Fig. 1.

\section{Competing interests}

The authors declare that they have no competing interests.

\section{Availability of data and materials}

The catalogue of Furet's observation is available as Additional file 1: Table S1.

\section{Consent for publication}

Not applicable.

\section{Ethics approval and consent to participate}

Not applicable.

\section{Funding}

Not applicable.

\section{Publisher's Note}

Springer Nature remains neutral with regard to jurisdictional claims in published maps and institutional affiliations.

Received: 28 June 2017 Accepted: 25 August 2017

Published online: 06 September 2017

\section{References}

Bakun WH (2005) Magnitude and location of historical earthquakes in Japan and implications for the 1855 Ansei Edo earthquake. J Geophys Res 110:B02304. doi:10.1029/2004JB003329

Bakun WH, Hopper MG (2004) Magnitudes and locations of the 1811-1812 New Madrid, Missouri, and the 1886 Charleston, South Carolina, earthquakes. Bull Seismol Soc Am 94(1):64-75

Beillevaire P (1999) Un missionnaire aux îles Ryûkyû et au Japon à la veille de la restauration de Meiji-Louis Furet (1816-1900). Archives des Missions étrangères, Études et documents (7), Série Histoire, Paris (in French)

Beillevaire $P$ (2013) Présences françaises à Okinawa: de Forcade (1844-1846) à Haguenauer (1930). Ebisu 49: 133-164. doi:10.4000/ebisu.815 (in French)

Demarée GR, Beillevaire P, Tsukahara T, Mikami T, Tagami Y, Zaiki M (2016) Les séismes à Okinawa: les observations du Père Louis Furet, missionnaire apostolique. Bull Soc Belge d'Astro Météo Phys Globe 132(1):2-10 (in French)

Frankel AD, Mueller CS, Barnhard TP, Perkins DM, Leyendecker EV, Dickman N, Hanson SL, Hopper MG (1996) National seismic-hazard maps. USGS Open-File Report 96-532
Fujimoto K, Midorikawa S (2005) Empirical method for estimating JMA instrumental seismic intensity from ground motion parameters using strong motion records during recent major earthquakes. J Inst Soc Safe Sci 7:241-246 (in Japanese with English abstract)

Headquarters for Earthquake Research Promotion, Cabinet Office, Government of Japan (2005) Japan seismic hazard information station. http:// www.j-shis.bosai.go.jp/. Accessed 8 June 2017

Historiographical Institute, Okinawa Prefectural Library (1984) Record of US Commodore Matthew Perry's visit to Ryukyu (2). The historical materials of Okinawa prefecture: Premodern era, vol 3. Okinawa Prefecture Education Board (in Japanese)

Imamura A (1913) Kikai Island earthquake of 1911 (Meiji 44th). Bull Imper Earth Invest Commit 77:88-102 (in Japanese)

JMA (2002) History of earthquake observation and data processing services. Q J Seismol 65(Suppl):1-401 (in Japanese)

JMA Seismic Intensity Catalogue (2017) JMA. http://www.data.jma.go.jp/svd/ eqdb/data/shindo/index.php. Accessed 8 June 2017

Kanai K, Suzuki T (1968) Expectancy of the maximum velocity amplitude of earthquake motions at bed rock. Bull Earth Res Inst 46:663-666

Kawasumi H (1951) Measures of earthquake danger and expectancy of maximum intensity throughout Japan as inferred from the seismic activity in historical times. Bull Earth Res Inst 29:469-482

Kawasumi H (1952) Energy law of earthquake occurrence in the vicinity of Tokyo. Bull Earth Res Inst 30:325-330

Kyuyo-Kenkyu-kai (1974) Translated version of "Kyuyo". Kadokawa Shoten, Tokyo (in Japanese, original title translated)

Miyazawa M, Mori J (2009) Test of seismic hazard map from 500 years of recorded intensity data in Japan. Bull Seismol Soc Am 99:3140-3149. doi:10.1785/0120080262

Nakamura S (1925) The great earthquake of S.E. Japan on 1 Sept 1923. Bull Imper Earthq Invest Committ 100A: 67-140. http://www.city-net.or.jp/ shinsai_htmls/pages/shinsai_kou/shinsai_kou_071.html. Accessed 8 June 2017 (in Japanese)

Nakamura M, Matsuura RS (2011) The 1855 Ansei-Edo earthquake: damages and seismic intensity map. Hist Earthq 26:33-64 (in Japanese)

Nojima N (2014) Conditional prediction equations for duration of specified intensity levels under predicted or observed JMA seismic intensity. J Jpn Assoc Earthq Eng 14(5):5_50-5_67 (in Japanese with English abstract)

Sato Y (1955) On the direction of earthquake sound. Zisin 2(8):149-154 (in Japanese)

Si H, Midorikawa S (1999) Attenuation relationships of peak ground acceleration and velocity considering effects of fault type and site condition. $J$ Struct Constr Eng AIJ 523:63-70 (in Japanese)

Sugimoto T (2000) Kashmir online manual. http://www.kashmir3d.com/kash/ manual/. Accessed 8 June 2017

Wakamatsu K, Matsuoka M (2013) Nationwide 7.5-arc-second Japan engineering geomorphologic classification map and Vs30 zoning. J Disaster Res 8(5):904-911

\section{Submit your manuscript to a SpringerOpen ${ }^{\circ}$ journal and benefit from:}

- Convenient online submission

Rigorous peer review

- Open access: articles freely available online

- High visibility within the field

- Retaining the copyright to your article

Submit your next manuscript at springeropen.com 